\title{
A COMPARATIVE STUDY BETWEEN ROUTINE INSERTIONS OF SUBHEPATIC DRAIN VERSUS NO DRAIN AFTER ELECTIVE LAPAROSCOPIC CHOLECYSTECTOMY
}

\section{Subhadip Sarkar*}

\section{Assistant Professor, Department of Surgery, ESIC-PGIMSR, Joka, Kolkata.} ${ }^{*}$ Corresponding Author

ABSTRACT Introduction: Laparoscopic cholecystectomy is the mainstay of treatment in symptomatic cholelithiasis. Surgeons are still following the old habit of routine Subhepatic drainage following laparoscopic cholecystectomy (LC). However, routine drainage after LC is still a debatable issue. This study aims at evaluating the effects of Subhepatic drainage after standard laparoscopic cholecystectomy in terms of various post-operative parameters.

Materials \& methods: The study was conducted at the department of General Surgery, ESIC-PGIMSR, Joka, Kolkata from January 2018 to March 2020. We selected 120 patients with symptomatic cholelithiasis \& divided them into 2 groups; each having 60 patients, with drain \& without drain respectively. Age \& sex distribution of the patients, post-operative abdominal pain \& right shoulder tip pain, post-operative wound infection, subhepatic collection ( 24 \& $72 \mathrm{hrs}$ after surgery) \& post-surgical hospital stay were measured in both groups. Data were analyzed by appropriate statistical tests.

Results: We found the incidence of laparoscopic cholecystectomy was highest in the $5^{\text {th }}$ decade \& more common in women. The incidence of post-surgical abdominal pain \& subhepatic collection were greater in the group of patients with drain in situ which was statistically significant also. Moreover, inserting drain showed increased incidence of post operative wound infection \& hospital stay, though these were statistically insignificant. More patients in the non drain group showed post-operative right shoulder tip pain in comparison to the drain group but that was also statistically insignificant.

Conclusion: The decision of inserting drain should be taken judiciously on the basis of individual case scenario. The generalized approach of putting abdominal drain after every standard laparoscopic cholecystectomy is not at all beneficial.

\section{KEYWORDS : cholelithiasis, drain, laparoscopic cholecystectomy}

INTRODUCTION:

Laparoscopic cholecystectomy [LC] is the gold standard treatment for cholelithiasis. It was introduced in mid 1980's [1]. The major advantages of LC includes less post-surgical pain, shorter post-operative hospital stay, earlier return to normal activities \& better cosmetic outcome [2]. The importance of surgical drainage after laparoscopic cholecystectomy is an unresolved issue till now. Similarly, in laparoscopic cholecystectomy also, there is lack of strong evidence regarding usefulness of drain. Surgeons are divided among themselves regarding the use of drain after LC. Most surgeons habitually place prophylactic subhepatic drains in order to detect early complications like post-operative haemorrhage \& leakage of bile. However, evidence based data do not support the routine use of prophylactic drainage in majority of the abdominal surgical procedures $[3,4,5]$. Few surgeons never place a drain, based on their personal experience and beliefs [6]. Moreover, some surgeons prefer an individual case based approach.

The objective of our present study is to evaluate the effects of subhepatic drainage after standard laparoscopic cholecystectomy in terms of various parameters like postoperative abdominal pain, right shoulder tip pain, postoperative wound infection, post-operative subhepatic collection \& average hospital stay.

\section{MATERIALS \& METHODS:}

This prospective study was conducted at the department of General Surgery in ESIC-PGIMSR, Joka from January 2018 to March 2020. 120 patients, who were diagnosed with symptomatic gall stone disease both clinically \& radiologically, were included in this study. They were randomly divided into 2 groups of 60 patients each, according to the presence \& absence of drain. Randomization was done by toss a coin method. All patients underwent standard laparoscopic cholecystectomy by the same surgical team. Prior to inclusion in the study groups, informed consents were obtained from all the patients under the supervision of institutional ethical committee. Certain exclusion criteria were also set beforehand.
EXCLUSION CRITERIA:

1. Age $<16$ yrs \& $\geq 70$ yrs.

2. H/O previous upper abdominal surgeries.

3. Symptomatic cholelithiasis with deranged LFT.

4. Acalculous cholecystitis.

5. Gangrenous cholecystitis.

6. Comorbidities like cirrhosis of liver, Ascites \& Coagulopathy.

7. Anesthetic fitness with ASA grading of 3 and above.

Standard post-operative care was given to all patients including antibiotics, analgesics \& wound care as per institutional protocol. Both groups were compared and analyzed on the basis of age \& sex distribution, post-operative complications like abdominal \& right shoulder tip pain, wound infection, subhepatic collections \& post-operative hospital stay.

\section{RESULT:}

The results were analyzed with SPSS for windows version 26 \& the differences between groups were compared with appropriate statistical test. P-value less than 0.05 were regarded as statistically significant.

During the 26months period, 120 patients who underwent laparoscopic cholecystectomy were studied. The data were meticulously collected \& analyzed.

Age distribution:

Table 1: age distribution of patients in both drain \& nondrain group.

\begin{tabular}{|c|c|c|c|}
\hline $\begin{array}{c}\text { Age group } \\
\text { (yrs) }\end{array}$ & Drain (n=60) & No drain (n=60) & Total \\
\hline$(16-19)$ & $4(6.67 \%)$ & $3(5 \%)$ & $7(5.83 \%)$ \\
\hline$(20-29)$ & $11(18.33 \%)$ & $13(21.67 \%)$ & $24(20 \%)$ \\
\hline$(30-39)$ & $14(23.33 \%)$ & $13(21.67 \%)$ & $27(22.5 \%)$ \\
\hline$(40-49)$ & $18(30 \%)$ & $16(26.67 \%)$ & $34(28.33 \%)$ \\
\hline$(50-59)$ & $10(16.67 \%)$ & $11(18.33 \%)$ & $21(17.5 \%)$ \\
\hline$(60-69)$ & $3(5 \%)$ & $4(6.67 \%)$ & $7(5.83 \%)$ \\
\hline
\end{tabular}

Note: Maximum no of patients belong to age group $(40-49) y r s$ in both groups

Sex distribution: 


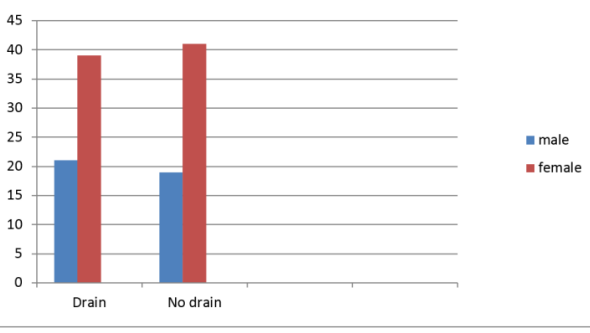

Figure 1: sex distribution of patients in both groups.

Sex distribution of patients in both the groups shows gall stone disease is more common in females.

Post-operative abdominal pain ( $24 \mathrm{hrs}$ after surgery):

Post-surgical abdominal pain was assessed via visual analogue scale (VAS). The pain score goes thus:-

Grade 0: no pain

Grade 1: slight pain

Grade 2: average pain

Grade 3: more than average pain

Grade 4: moderate pain

Grade 5: severe pain

Figure 2: visual analogue scale

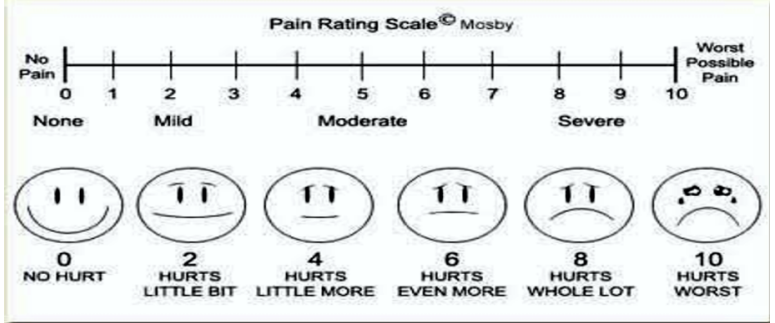

Table 2: post-operative abdominal pain (24 hrs after surgery) in both groups of patients

\begin{tabular}{|c|c|c|c|}
\hline Pain & Drain $(\mathrm{n}=60)$ & No drain $(\mathrm{n}=60)$ & Total \\
\hline G0 & $0(0 \%)$ & $0(0 \%)$ & $0(0 \%)$ \\
\hline G1 & $10(16.67 \%)$ & $14(23.33 \%)$ & $24(20 \%)$ \\
\hline G2 & $11(18.33 \%)$ & $31(51.67 \%)$ & $42(35 \%)$ \\
\hline G3 & $27(45 \%)$ & $10(16.67 \%)$ & $37(30.83 \%)$ \\
\hline G4 & $12(20 \%)$ & $5(8.33 \%)$ & $17(14.17 \%)$ \\
\hline G5 & $0(0 \%)$ & $0(0 \%)$ & $0(0 \%)$ \\
\hline
\end{tabular}

Note: Chi square statistics 20.8836, p-value 0.0001 (<0.05)

In our study, VAS median grade in patients with drain was G3 (45\%), followed by G4 (20\%). VAS median grade without drain group was G2 (51.67\%), followed by Gl (23.33\%) \& G3 (16.67\%). The p-value came as $0.0001(<0.05)$. So, there was statistically significant difference between these two groups.

Post-operative wound infection:

Table 3: Post-operative wound infection in both groups.

\begin{tabular}{|c|c|c|c|}
\hline Wound infection & Drain (n=60) & No drain (n=60) & -value \\
\hline Present & $3(5 \%)$ & $1(1.67 \%)$ & 0.309 \\
\hline Absent & $57(95 \%)$ & $59(98.33 \%)$ & \\
\hline
\end{tabular}

In this study, wound infection was observed in 3 patients (5\%) in the drain group and 1 patient $(1.67 \%)$ in the non-drain group. As evident from the p-value, this difference was statistically insignificant.

\section{Post-operative right shoulder tip pain:}

Table 4: right shoulder tip pain after surgery in both groups. \begin{tabular}{|l|l|l|l|}
\hline Right shoulder pain & Drain $(\mathrm{n}=60)$ & No drain $(\mathrm{n}=60)$ & $\mathrm{p}$-value \\
\hline
\end{tabular}

\begin{tabular}{|c|c|c|c|}
\hline Present & 1 (1.67\%) & 4 (6.67\%) & \multirow{2}{*}{0.170} \\
\cline { 1 - 3 } Absent & $59(98.33 \%)$ & $56(93.33 \%)$ & \\
\hline
\end{tabular}

In the present study, right shoulder tip pain as a post-surgical complication was observed in 1 patient $(1.67 \%)$ in the drain group \& in 4 patients (6.67\%) in the no drain group. However, no statistically significant difference was observed between these 2 groups here.

Post-operative subhepatic collection:

Table 5: Post of subhepatic collection after $24 \& 72 \mathrm{hrs}$ in both groups.

\begin{tabular}{|c|c|c|c|c|l|}
\hline \multirow{2}{*}{$\begin{array}{c}\text { Subhepatic } \\
\text { collection in } \mathrm{ml}\end{array}$} & \multicolumn{2}{|c|}{ With drain } & Without drain & p-value \\
\cline { 2 - 6 } & Mean & SD & Mean & SD & \\
\hline 24 hrs post-op & 30.2 & 3.76 & 24.2 & 2.62 & $<0.0001$ \\
\hline 72 hrs post-op & 25.4 & 2.21 & 22.8 & 3.27 & $<0.0001$ \\
\hline \multicolumn{3}{|c|}{ Note: both are statistically significant } \\
\hline
\end{tabular}

In our study, mean subhepatic collection noted in patients with drain, $24 \mathrm{hrs}$ after surgery, was $30.2 \mathrm{ml} \&$ after $72 \mathrm{hrs}$ of surgery was $25.4 \mathrm{ml}$. However, mean subhepatic collection in patients without drain, after $24 \& 72 \mathrm{hrs}$ of surgery were $24.2 \mathrm{ml} \& 22.8$ $\mathrm{ml}$ respectively. This difference was statistically significant in both cases, as per p-value calculation from student's unpaired t-test.

Post-operative hospital stays (days):

Table 6: Post-operative hospital stays in both groups.

\begin{tabular}{|c|c|c|c|c|c|}
\hline \multirow{2}{*}{ Variable } & \multicolumn{2}{|c|}{ With drain } & \multicolumn{2}{c|}{ Without drain } & p- \\
\cline { 2 - 5 } & Mean & SD & Mean & SD & \\
\hline Hospital stay (days) & 3.2 & 0.403 & 3.1 & 0.302 & 0.635 \\
\hline
\end{tabular}

In the present study, mean hospital stay in patients with drain was 3.2 days whereas; in patients without drain was 3.1 days. The p-value came as $0.635(>0.05)$. So, this difference was statistically insignificant.

\section{DISCUSSION:}

Subhepatic drainage after cholecystectomy, open or laparoscopic, is still an unsolved debate. In our study, the most commonly affected age group is (40-49) yrs; with $28.33 \%$ of cases. Similarly, in studies conducted by Aman Nagpal et al [7] \& Mandeep Singh et al [8], the maximum numbers of cases are in the $4^{\text {th }}$ decade.

In this study, we found that overall $66.67 \%$ of cases were female \& $33.33 \%$ cases were male. Similar sex preponderance in favour of females was observed by Dumlu et al [9] in their study with 5:1 (F: M ratio). The study done by Aman Nagpal et al [7] also showed the male female ratio as 1:3.

In the present study, post-operative abdominal pain was evaluated using the visual analogue scale. We observed higher pain score with statistically significant difference in the drain group than the no-drain group; $24 \mathrm{hrs}$ after surgery. The increase in pain following drain insertion is probably because of the peritoneal irritation \& irritation of skin at the entry point of drain by a foreign body. This is in concurrence with the meta-analysis by C.S.Wong et al [10].

In this study, the incidence of early post-operative right shoulder tip pain was found to be higher in the no drain group than the group of patients with drain. However, this was statistically insignificant. Guruswamy et al [11] in a metaanalysis also reported decreased early post-operative shoulder pain in the drain group that was not significant statistically \& reversed in the late post-operative period.

$5 \%$ patient in the drain group developed wound infection in the post-operative period whereas, $1.67 \%$ patient in the no drain group developed the same. No statistically significant difference was found here between two groups. Similar observations were noted in studies done by Lewis \& also in a study done by Druart \& Huguier [12]. The increased rate of wound infection is probably due to ascending infection via the drain. 
Table 7: wound infection in different studies.

\begin{tabular}{|c|c|c|}
\hline Study & Drain & Without drain \\
\hline Lewis & $08 / 246$ & $06 / 248$ \\
\hline Druart & $01 / 26$ & $0 / 24$ \\
\hline Huguier & $03 / 50$ & $02 / 50$ \\
\hline Present study & $03 / 60$ & $01 / 60$ \\
\hline
\end{tabular}

In the present study, mean subhepatic fluid collection after 24 hrs of surgery were $30.2 \mathrm{ml} \& 24.2 \mathrm{ml}$ in drain \& non-drain group respectively. After $72 \mathrm{hrs}$ of surgery, mean subhepatic collection in the drain group was $25.4 \mathrm{ml} \& 22.8 \mathrm{ml}$ in the other group. Both were found to be statistically significant. A study conducted by Shamim [13] showed similar findings. However, study done by Picchio [14] showed $30 \mathrm{ml}$ of mean subhepatic collection in both drain \& without drain group. As per many authors, post-cholecystectomy collection in the subhepatic space are on the whole small, rapidly reabsorbed \& essentially similar in size \& number whether a drain is used or not. They also suggest that drain provokes leakage from superficial biliary ductules damaged by dissection and contend that without drainage it would rapidly wall off. In this way, higher volume of subhepatic fluid collection in the patients with drain can be explained.

We observed mean hospital stay was 3.2 days \& 3.1 days in drain \& without drain group respectively. However, this was not significant statistically, as shown by the p-value. Similar observations were obtained in the study conducted by Lewis \& also in study done by Bawahab [15].

Table 8: mean hospital stay in different studies.

\begin{tabular}{|c|c|c|c|c|}
\hline \multirow{2}{*}{ Study } & \multicolumn{2}{|c|}{ With drain } & \multicolumn{2}{c|}{ Without drain } \\
\cline { 2 - 5 } & $\mathrm{N}$ & Mean (SD) & $\mathrm{N}$ & Mean (SD) \\
\hline Lewis & 246 & $5.9(2)$ & 248 & $5.5(2)$ \\
\hline Bawahab & 38 & $4.48(2.18)$ & 65 & $2.50(2.20)$ \\
\hline Present & 60 & $3.2(0.403)$ & 60 & $3.1(0.302)$ \\
\hline
\end{tabular}

\section{CONCLUSION:}

From this study, we can conclude that the incidence of laparoscopic cholecystectomy is highest in the $5^{\text {th }}$ decade $\&$ is more common in females. Insertion of drain causes statistically significant increase in post-surgical abdominal pain \& subhepatic collection. Moreover, putting drain shows increased incidence of post-operative wound infection \& postoperative hospital stay, though they are not significant statistically.

So, the routine use of drain after standard laparoscopic cholecystectomy has nothing to offer. It has to be used judiciously on the basis of the merit of individual cases, rather than putting it in all cases in general. It is always reasonable to avoid drain insertion when a dry operative field is obtained at the end of the procedure.

\section{Funding: none}

Conflict of interest: none

\section{REFERENCES}

1. Muhe E (1986): The first cholecystectomy through the laparoscope. Langenbecks Archive of Surgery 396 (1): 804

2. Shaffer, E.A. (2006).Epidemiology of gall bladder stone disease. Best practice \& Research Clinical Gastroenterology, 20 (6), 981-996. doi: 10.1016/ j.bpg. 2006.05.004

3. Launay-Savary MV, Slim K. Evidence-based analysis of prophylactic abdominal drainage. Annales de Chirurgie 2006; 131: 302-305.

4. Karliczek A Jesus EC, Matos D. Drainage or nondrainage in elective colorectal anastomosis: a systematic review and meta-analysis. Colorect Dis JAssoc Coloproctol Great Britain Ireland 2006; 8: 259-265.

5. Petrowsky H, Demartines N, Rousson V. Evidence-based value of prophylactic drainage in gastrointestinal surgery: a systematic review and meta-analyses. Ann Surg 2004; 240: 1074-1084; discussion 84-85.

6. Askew JA. Survey of current surgical treatment of gall stones in Queensland. Aust NZJ Surg.2005; 75:1086-9.

7. Nagpal A, Goyal S, Abbey L \& Singh A. (2012). Drainage in Cholecystectomy: Required or Not? A Comparative Randomized Study in Northern Indian Subjects. World Journal of Laparoscopic Surgery with DVD; 5: 63-66. doi: 10.5005/jp-journals-10007-1151.

8. Singh M, Singh K, Chawla IS. (2017). Laparoscopic cholecystectomy with and without drainage- a comparative clinical study. International Journal of
Contemporary Medical Research 4 (1):117-120.

9. Dumlu E.G, Kiyak G, Bozkurt B, Tokac M, Gurer A \& Kilic M. (2013). Is a Drain Required after Laparoscopic Cholecystectomy? The Eurasian Journal of Medicine; 45(3):181-184. doi: 10.5152/eajm.2013.37.

10. Wong CS, Cousins G, Duddy JC \& Walsh SR. (2015). Intra-abdominal drainage for laparoscopic cholecystectomy: A systematic review and metaanalysis. International Journal of Surgery; 23:87-96. doi: 10.1016/ j.ijsu. 2015. 09.033

11. Gurusamy KS, Samraj K, Mullerat P, Davidson BR (2007). Routine abdominal drainage for uncomplicated laparoscopic cholecystectomy. Cochrane Database of Systematic Reviews. doi: 10.1002/14651858.cd006004.pub2.

12. Jackson PG, Evans SRT. The Biliary System, In: Townsend Jr CM, Beauchamp RD, Evers BM, Mattox KL (Eds). Sabiston Textbook of Surgery. $19^{\text {th }}$ ed. Philadelphia: WB Saunders Pub; 2012: p.1597-1643.

13. Shamim M. Routine sub-hepatic drainage versus no drainage after laparoscopic cholecystectomy: open, randomized, clinical trial. Indian J Surg. 2013;75: 22-27.

14. Picchio $\mathrm{M}$ et al. Meta-analysis of Drainage versus no drainage after laparoscopic cholecystectomy. JSLS.2014; 4 (18): 7-9.

15. Bawahab MA et al. Drainage vs non-drainage after cholecystectomy for acute cholecystitis: a retrospective study. J Biomed Res. 2014; 28(3): 240-45. 